\title{
IDENTIFICATION AND CONSERVATION OF A RARE ISLAMIC TEXTILE DECORATED WITH METALLIC YARNS
}

\author{
Ahmed, $\mathrm{H}$. \\ Lecturer Conservation dept., Faculty of Archeology, Cairo University, Egypt \\ E-mail: harbyezzeldeen@yahoo.com
}

\begin{abstract}
A rare Islamic textile decorated with two types of metallic yarns date back to 1327 Hijri. This object is from the textiles collection of Sheikh Yusuf Jameel museum in Saudi Arabia. These collections are housed in uncontrolled storage, in terms of variation and fluctuation humidity, temperature and air pollution throughout the year. These storage conditions have had a passive effect on the metallic and natural yarns causing damage. The nature of the surface metals and the nature of the corrosion products were studied by scanning electron microscopy with energy-dispersive $X$-ray microanalysis (SEM/EDS). A close examination of the textile was followed by various analyses in order to develop a plan for conservation treatment. This research shows the practical strategies which have to be followed in maintaining and conserving textiles in uncontrolled storage. The effects of cleaning materials on the natural dyes were tested, including different types of solvents used to remove the corrosion layer on the metallic yarns. The process of maintenance and restoration has been recorded beginning with the historical record of the textile to the present cleaning process. A new mounting system for display as in Sheikh Yusuf Jameel museum is described.
\end{abstract}

Keywords: Metallic yarns, Corrosion, Cleaning, SEM, Natural dyes, Mounting.

\section{Introduction}

The Ottoman period provided a rich treasure of different types of textiles. Many of these textiles contain metal yarns as decorations, usually made from gilded silver, silver, or brass. Decorative metals have been incorporated into textiles for thousands of years. Embroideries were one of the most sumptuous kinds of textiles produced in sixteenth- century Europe, and among these costly goods, gold embroideries were the most precious. Metal yarns deteriorate over time and corrode due to chemical attack by different corrosive factors such as high and fluctuating relative humidity, air pollutants and elevated temperatures [1] [2] [3] [4] [5] [6] [7] [8] [9]. Textiles employing metal are generally in poorer condition than those that do not contain metal, because of extra stresses from the high mass of the fabric and the multiplicity of degradation processes. The condition of the textile containing metal yarns depends on various factors related to the quality of the materials from which the yarns made, their manufacturing techniques, and the surrounding environmental factors. These types of objects, which are formed of composite 
materials of different origin and nature, pose a major conservation challenge [10] [11] [4] [12] [7] [8] [9]. For effective restoration, conservation planning and treatment of such composite objects, it is necessary to carry out a diagnosis of the materials that constitute the object. For this type of composite object, many studies have focused on investigating the technology and types of materials for

\subsection{Description of the object}

This object dates back to the late Ottoman era as it was manufactured in 1327 Hijri. The object was made in Egypt. It contains different types of decorative motifs such as floral, geometric and writing. In the decorations using two types of metal yarns (black and yellow yarns), the structure of metal
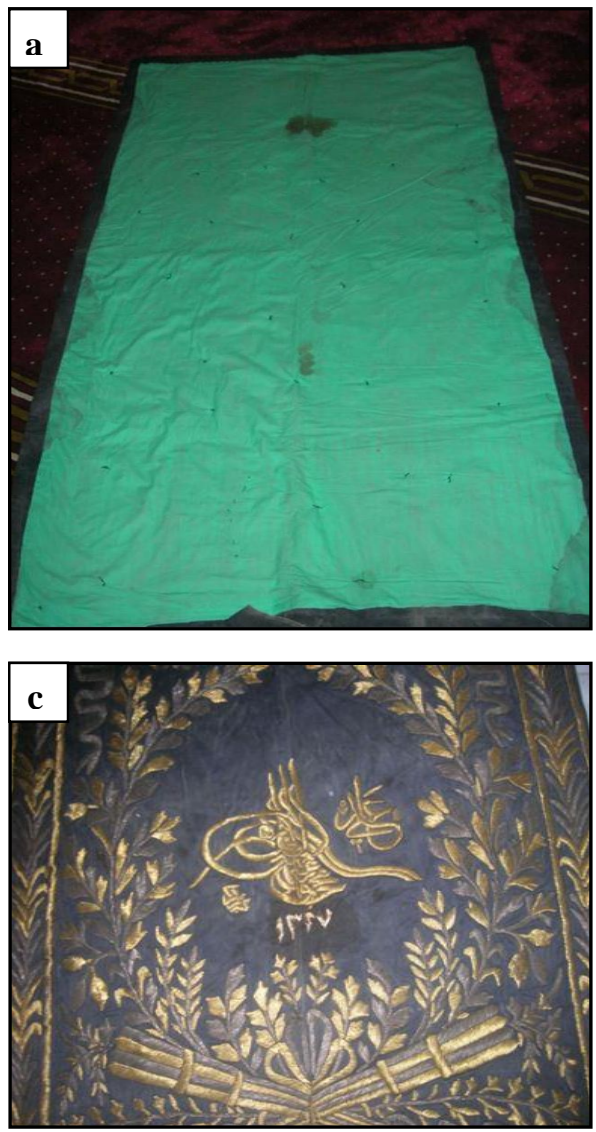

Figure (1) Ottoman textile object from the front and behind showing the decorations, colors, and some damaging forms

\section{Examination of metal threads}

Scanning electron microscopy with energy-dispersive $\mathrm{X}$-ray microanalysis (SEM/EDS) is the most frequently used metal yarns [4] [13]. The corrosion products of metal are mainly crystalline materials: oxides, hydroxides and simple or basic metallic salts. The metals used to make metal yarns found in or historical textiles are compounds containing covalent bonds with varying degrees of ionic covalent compounds of water solubility [1].

yarns is a solid metal wire. The object is contains the different colors such as black and red color. A visual inspection showed the object to have accumulated dust and dirt mainly due to many years of poor storage under unsuitable and uncontrolled environment, fig. (1-a, b, c, d).
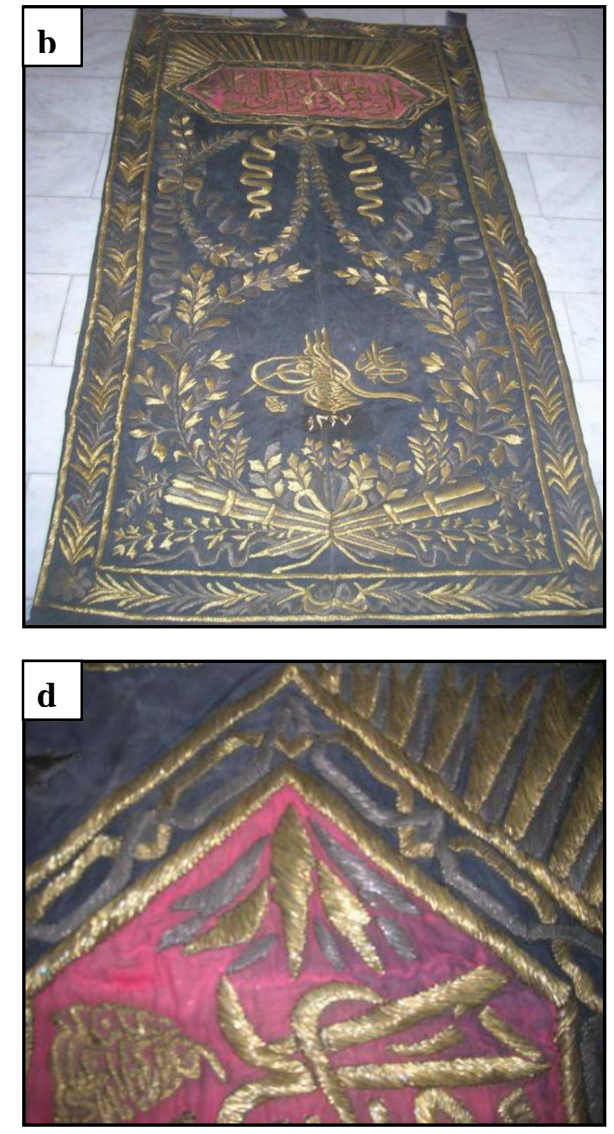

analytical technique for determining of the composition of metal yarns. Where, the energy-dispersive system (EDS), 
giving qualitative and quantitative information. Furthermore, SEM images provide a characteristic surface morphology and are useful for judging the surface structure of the investigated

\section{Results}

The results of SEM investigations proved that the object was made of cotton fibers. The SEM images show that the embroidery or metal yarn are fragile and in very poor condition. It also contains a black stain as shown previously in fig (1). Furthermore, the images show that there sample, fibers identification and the damaging aspects. [14] [15] [16]. The morphology of the surface of the fibers was investigated using (Joel- Scanning Electron Microscope).

is a corrosion layer on the surface of the metal yarn, fig. $(2-a, b, c)$. On the other hand, EDX results show that the metal yarns in sample one were manufactured from different type of elements such as copper $(\mathrm{Cu})$, zinc $(\mathrm{Zn})$ as shown in fig. $(3-a, b, c)$.

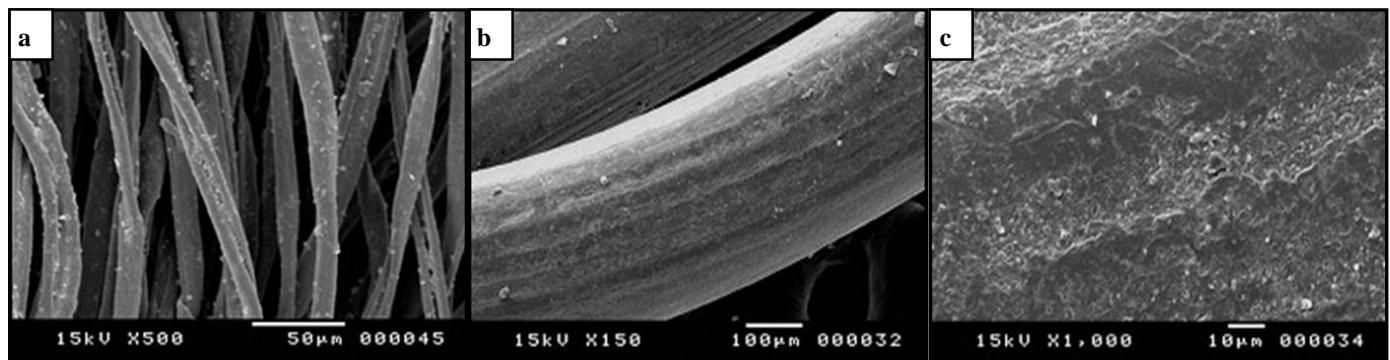

Figure (2) SEM images $\underline{\mathbf{a}}$ natural cotton, dust and other abrasive of damage, $\underline{\mathbf{b}} \&$ c showing the metal yarn and we can see the corrosion on the yarn.

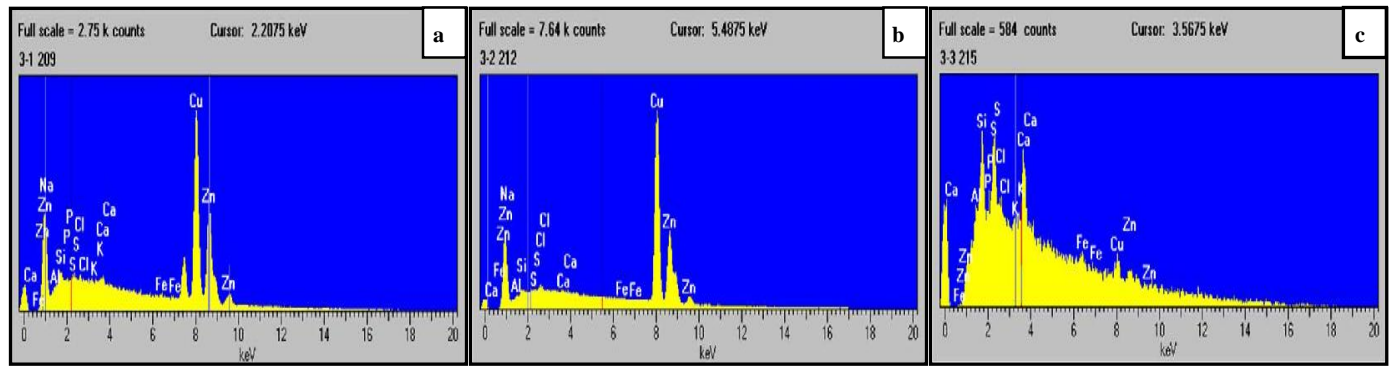

Figure (3) EDX patterns $\underline{\mathbf{a}}$ yellow metal yarn, $\underline{\mathbf{b}}$ black metal yarn \& $\underline{\mathbf{c}}$ natural fiber

\section{Conservation Procedures}

\subsection{Testing the stability of dyes}

To test the stability of the natural dyes to wet cleaning, green canvas lining was removed, the object showed severe dryness. A piece of cotton wrapped round a wooden stick was immersed into the cleaning solutions

\subsection{Mechanical cleaning}

The aim of conservation cleaning is to remove harmful soils, which may be disfiguring or causing physical or chemical damage to a textile. Selection of the appropriate cleaning method depends on the nature of the soil present, and on the materials, structure, and condition of the textile. Thorough testing should and placed in contact with the colorful parts of the embroiderers. Each color was individually tested. It was found that all the dyes were stable and did not bleed with the wet cleaning solution.

always be carried out first to determine the response of the textile to cleaning agents and to identify the most suitable method [17] [4] [5] [12] [7] [8] [9]. Various types of fine brushes are used to remove free dust and dirt from the upper layers of the fabric. Surface dust was removed by using a vacuum cleaner [2]. 


\subsection{Removing the corrosion}

Different types of solvents such as acetone, carbon tetrachloride and methanol were used in order to remove the corrosion from the metal yarn. A piece of cotton wrapped round a wooden stick was immersed into the solvent solutions and placed it in contact with the surface of the metal yarn. Then, the cotton swab was gently rubbed on the surface of the yarns. Different types of brushes were used to remove all the corrosion products.

\subsection{Coating and isolated the metallic threads}

After removing of old background fabric and cleaning the metal yarn, it was coated with Paraloid B-82 10\% (ethyl methacrylate/methyl acrylate copolymer). This process was done to isolate and
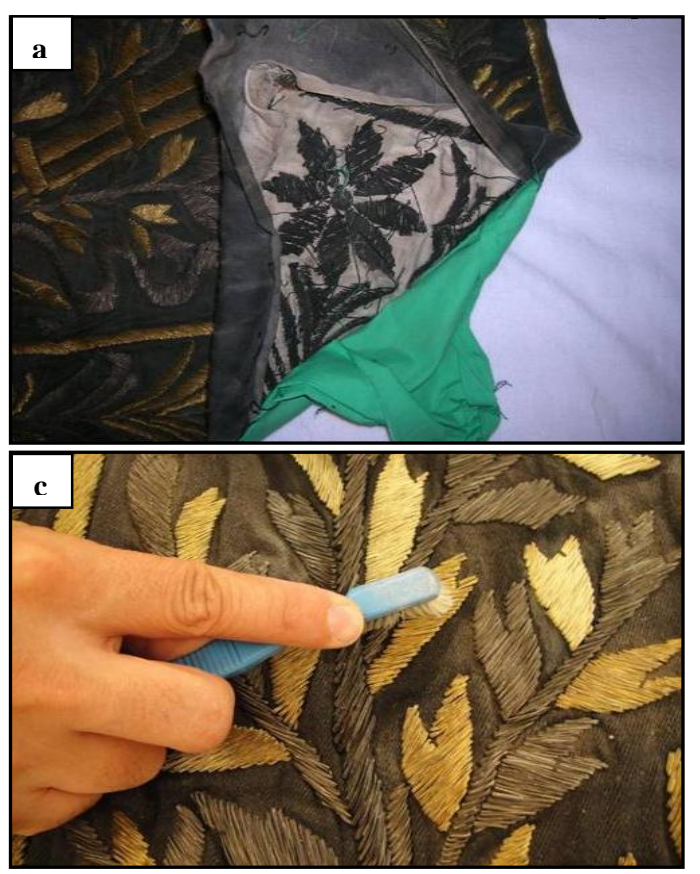

Figure (4) $\underline{\mathbf{a}}$ removing of old background fabric, $\underline{\mathbf{b}} \& \underline{\mathbf{c}}$ cleaning process of metal yarn by solvents $\underline{\mathbf{d}}$ protection of metal yarn by using Paraloid B- 82

\subsection{Wet cleaning procedure}

A temporary wash bath was built by using four wooden tires and, lining the bath by polyethylene. This cleaning procedure used water with other detergent agents, to assist the cleaning process. The ratio was one part detergent Synperonic N to 100 parts of distilled water. The water was agitated for 15 minutes to allow it to penetrate between

\subsection{Drying process}

To dry the object without distortion, we experimented with a Japanese tissue sandwich using different tissues (usugami or gampi) applied crossgrain or parallel-grain to the textile with varying amounts of pressure. Then the protect the metallic yarn from the effects of the relative humidity during storage or when the artifact is displayed in the museum, all of these steps are shown in fig. (4-a, b, c, d).

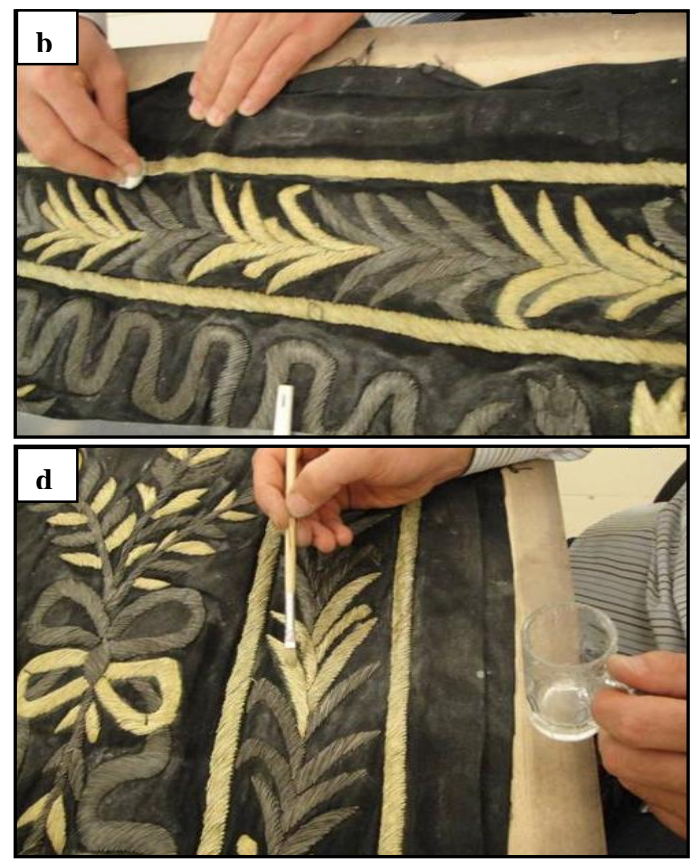


sufficiently large in comparison to the size and surface area of the drying textile; and by ensuring that water vapor is removed as soon as it is formed with the help of dehumidifiers, fans and/or effective ventilation [20] [1], these steps are shown in fig. $(5-a, b, c)$.

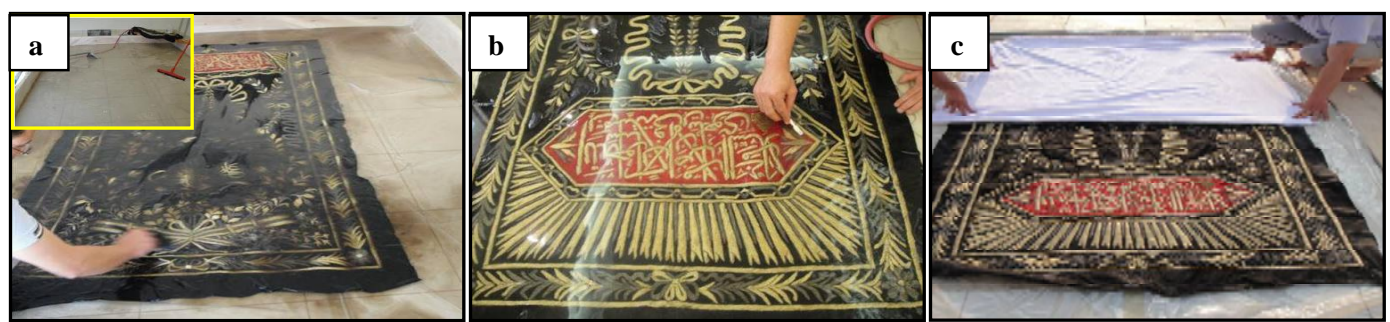

Figure (5) $\underline{\mathbf{a}}, \underline{\mathbf{b}} \& \underline{\mathbf{c}}$ steps of, cleaning process of the textile in temporary bath and. drying process after cleaning

\subsection{The final support process}

A new linen support fabric was prepared and washed to remove chemical residues and prevent shrinkage at a later time due to humidity changes. The new linen fabric was ironed to remove creases. The new support was three layers adhered together by stitching (non woven textile between two layers of linen). The edges of the support fabric were perforated and the holes were reinforced by metallic rings. A wooden frame was used for mounting. The rings were fixed for easy stretching on the wooden frame. Thick cotton thread was used for fixing the linen support on the wooden frame, fig. $(6-a, b)$. The textile was positioned
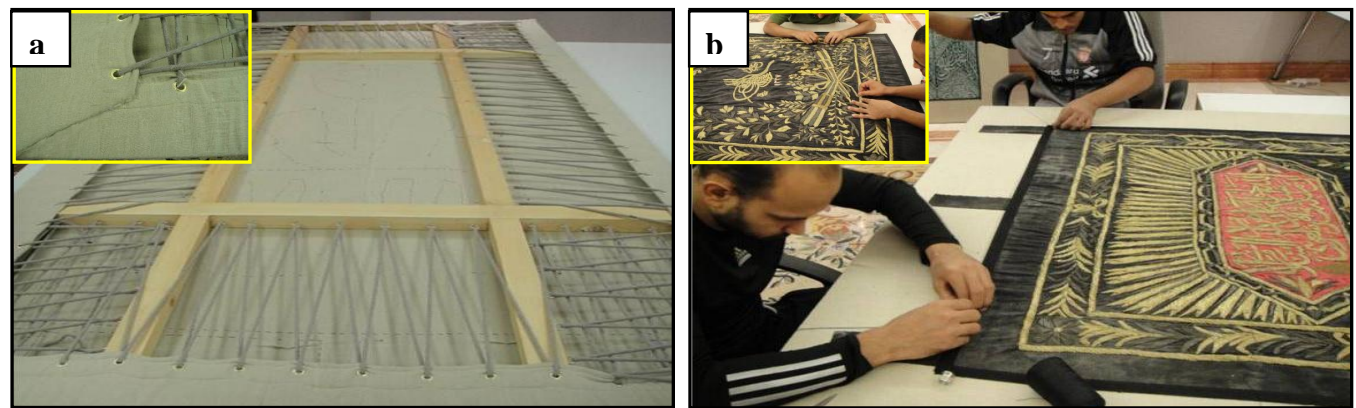

Figure (6) a preparing new linen support and attaching the textile on the support, $\underline{\mathbf{b}}$ metal yarn before cleaning and after cleaning in the red box

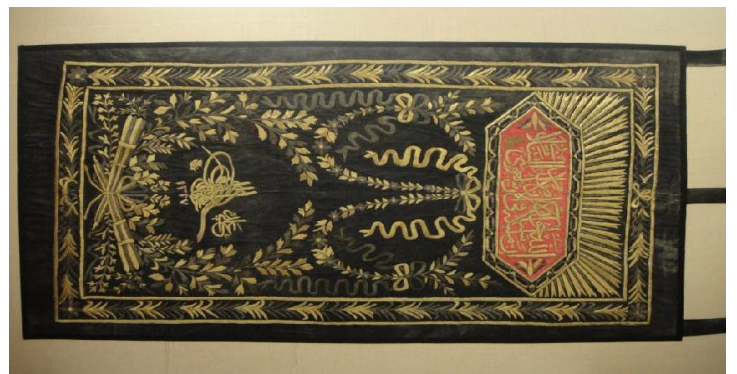

Figure (7) textile after cleaning, mounted on new linen support after completion of the conservation treatment 


\section{Discussion}

The investigation of the metal yarn surface using Scanning Electron Microscopy (SEM) shows that all the metal yarn is the typical structure of historical metal yarns, which is solid metal wire. Microscopic examination shows the layers of corrosion resulting from the impact of weather conditions in the uncontrolled storage environment. The results show that the metal yarn in sample was manufactured from different type of elements such as copper $(\mathrm{Cu})$, and zinc $(\mathrm{Zn})$. The results show that the main components of the sample are copper $(\mathrm{Cu})$ average $53 \%$, zinc $(\mathrm{Zn})$ average $37 \%$ which are the fundamental structure of the alloy. Furthermore, the EDX show other elements such as $(\mathrm{Cl})$ average $1 \%$, and $(\mathrm{Na})$ average 5\%. Also results show Carbon $(\mathrm{C})$ and Oxygen $(\mathrm{O})$. It is caused by the presence of corrosion compounds on the surface of metal yarn. The solvents such as acetone, carbon tetrachloride show effectiveness to remove the corrosion from the metal yarn more than ethanol.

\section{Conclusion}

The present article described the analysis and conservation treatment of a historic textile decorated with metal yarns. The textile is dated from the late Ottoman period. Analysis by SEM has shown that the textile was made of cotton decorated with metal yarns. The surface of the textile had an accumulation of dust and dirt affecting the mechanical properties and the appearance of the object, giving it a dull grey and opaque tone. The conservation treatment, which included the removal of corrosion and cleaning and mounting in a proper support, has increased the stability of the textile. Although there was a noticeable improvement of the appearance and integrity of the object after conservation, there was one type of dirt that could not be removed by wet or dry cleaning. After the cleaning and mounting, the textile is free from dirt, has become softer and it is aesthetically more pleasing. Physically, the wrinkles and folds are much less obvious. It is recommended that the textiles should be moved to museum storage as soon as possible for safe keeping of the pieces. It is also recommended that further research should be carried out to study the materials used in the manufacture of the textile, specifically the metallic yarn, the natural dyes and mordents.

\section{Acknowledgment}

This research is a part of private project of the author. The author would like to thank his team: Sabry Draz, Ibrham Elkoly, Mohamed Hosam, Madhat Samir, Abas Kabary and Mostafa Mohamed for their contributions.

\section{References}

[1] Balazsy, A. \& Eastop, D., (1998). Chemical principles of textile conservation, Routledge; $1^{\text {st }}$ ed., UK.

[2] Landi, S (1992). The textile conservator's manual, $2^{\text {nd }}$ ed., Routledge, London

[3] Hacke, A., Carr, C. \& Brown, A., (2005). Characterization of metal threads in renaissance tapestries, in: Ashton, J. \& Hallam, D., (ed.) Int. conf. on metals conservation "Metal 2004", National Museum of Australia Canberra ACT, pp: 415-426

[4] Bergstrand, M \& Hedhammar, E (2006) European metal threads in Swedish churches 1600-1751 construction and conservation, Studies in Conservation, Vol. 51 (1), pp: 11-28.

[5] Theile, J., Guarda, S. \& Croquevielle, E., (2004). Analysis, conservation and restoration of the metal threads used in Latin American colonial saints robes, in: Ashton, J. \& Hallam, D., (ed.) Int. conf. on metals conservation "Metal 2004", National Museum of Australia Canberra ACT, pp: 501-513

[6] Bergstrand, M. \& Hedhammar, K., (2000). A note on the analysis of gilded metal embroidery threads, Studies in Conservation. Vol. 45, (4), pp: 274-279

[7] Enguita, O., Climent-Font, A., Garcia, G., Montero, I., Fedi, M., Chiari, M. \& Lucarelli, F., (2002). Characterization of metal threads using differential PIXE analysis, Nuclear Instruments and Methods in Physics Resaerch, B 189, pp: 328-333.

[8] Rezić. I., Curković, L., Ujević, M., (2010). Simple methods for characterization of metals in historical 
textile threads, Talanta, Vol. 82 (1), pp: 237-244

[9] Karadag R., Torgan, E \& Yildiz, Y., (2012). Analyses of dye, weaving and metal thread in Ottoman silk brocades and their reproduction, in: $13^{\text {th }}$ Biennial Symposium, Textile Society of America, Washington, pp: 1-13

[10] Lee Yu, J., \& Koh, Y., (2003). Experimental study on the effect of wavelength in the laser cleaning of silver threads, Journal of Culture Heritage, Vol. 4, pp: 157-161.

[11] Boeck, J., Vereecken, V., \& Reicher, T., (1987). The conservation of Embroideries at institute royal du patrimoine artistique, in: Grimstad, K. (ed.) The conservation of tapestries and embroideries, Brussels, pp: 5-9.

[12] Bergstrand, M., Hedhammar, E. \& Nord, A., (1999). All that glitters is not gold: an examination of metal decorations on ecclesiastical textiles, ICOM 1999.

[13] Peranteau, A., Carlson, J., \& Mass, J., (2004). The technical analysis of two pieces of $17^{\text {th }}$ century English embroidery", in: Poul Wyth (ed.) Informing Preservation, Display and Interpretation, AHRC Research Center for Textile Conservation and Textile Studies, Archetype Publications Ltd, London, 2005, pp: 24-28.

[14] Jaro, M., (1990). Gold embroidery and fabrics in Europe: XI-XIV centuries', Gold Bulletin, Vol. 23, pp: 40-57.
[15] Jaro, M. \& Toth, A., (1991). Scientific identification of European metal thread manufacturing techniques of the $17^{\text {th }}-19^{\text {th }}$ century', Endeavour, Vol. 15, pp: 175-184.

[16] Jane, C., (2004). Optical and scanning electron microscopy techniques for the identification of hair fibers from Romano- Egyptian textile. in: Poul Wyth (ed.) Informing Preservation, Display and Interpretation, AHRC Research Center for Textile Conservation and Textile Studies, Archetype Publications Ltd, London, 2005, pp: 91-103.

[17] Lister, A., (1996). Guidelines for the conservation of textiles, English Heritage, London.

[18] Haward, S., (1994). An introduction of the wet cleaning of carpets, The International Perspective on Textile Conservation Report, ICOM, Amsterdam,

[19] Moes, Y., (1994). Tapestry cleaning by aerosol suction, The international perspective on textile conservation report, ICOM, Amsterdam

[20] Fletcher, S. \& Walsh, J., (1979). The treatment of three prints by whistler on fine Japanese, JAIC, Vol. 18, (2), pp: $119-126$

[21] Tronner, K., Nord, N., Sjostedt, J., \& Hydman, H., (2002). Extremely thin gold layers on gilded silver threads, Studies in Conservation, Vol. 47 (2), pp: 109-116. 